\title{
上層雲と高層気象要素との関係
}

\author{
来 海 徹 $\rightarrow$
}

\section{Studies on the Meteorological Elements of High Cloud}

\author{
T. Kimachi
}

(Yonago Weather Station)

Since the accurate height of high cloud is measured by balloon tracking, we can know the meteorological elements there from radiosonde data.

High cloud exists in the transitional layer between two air flows. This transitional layer has the temperature lapse rate of about $0.2 \sim 0.4^{\circ} \mathrm{C} / 100 \mathrm{~m}$.

From the fact that the balloon disappears at the top, inside, and base of the layer, the thickness of the layer seems to denote the thickness of high cloud but it follows, the thickness of the layer is not in so good proportion to the thickness by sight, and we must consider not only the thickness but also the density of the cloud particles.

We have no reliable data of humidity at higher level. Hair hygrometer doesn't work enough there, and in this paper the value is decided from temperature and humidity.

Temperature range of high cloud extends $-10 \sim-50^{\circ} \mathrm{C}$. This has a certain connection with the experiments on the growth of ice crystals.

By analysis of transitonal layer on time-isopleth, we can analyse the states of high cloud, and make it use for weather forecast. Here we show two cases, that is, developing and dissipating of high cloud. Relation between temperature lapse rate and state of the sky $\left(C_{H}\right)$ is given as one of the general results.

緒言

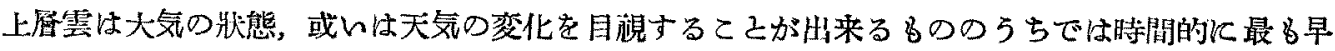

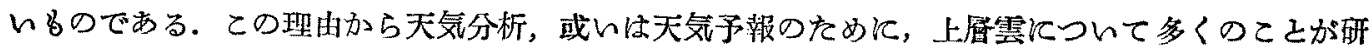
究されている．然し雲の高さ及び動き以外の上屋雲の持つ気像姴素を知るて之は困難であるため K, 雲の発生, 㒄等につんての研究はあまりなされていないよ5である.

ての論文ではラジオゲンデの気球が上曆雲に入つたてさが確認されれ場合をとりあげて，シジオ

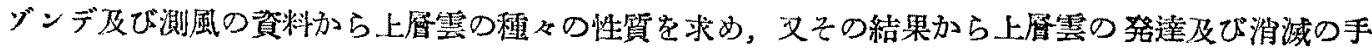
掛定得上 5 こした. 
上底雲高の観測方法が限定されているために資料が少いが一応の結果が梳たので報告する。

\section{§ 1. 筧 測 方 法}

上屏雲高を求めるには二点観測による方法，及び測高機による方法等があるが我ふには，乙れら の方法が用いられないので，測風気球が雲に入つたとさが確認された上きの高度を雲高己した。乙 の方法で高度を求める際には次のことを注意する必要がある。

1）上詹雲は高度が高いから気球が視力外になつたのか，雲に入つたのか明睹に区別出来婸合 がある。

2）淡い上首雲では雲に気球が入つても引続いて見える場合がある.

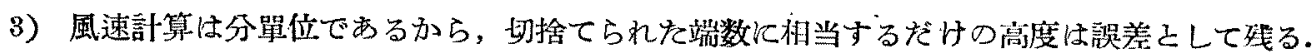

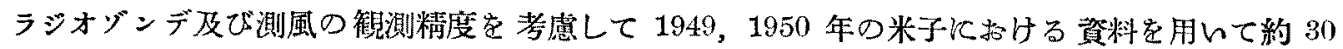
の例定得灰。

\section{§2. 上層 霛 高}

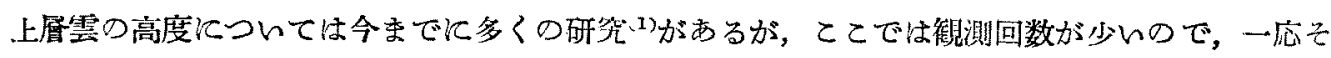
れらと此較する意味で記しておく.（Table 1)

Table 1. Mean height of high cloud at Yonago $(\mathrm{km})$.

\begin{tabular}{l|r|r|r|r|r|r|r|r}
\hline & \multicolumn{1}{|c|}{$C_{i}$} & $C_{i s t}$ & $C_{i c u}$ & & $C_{i}$ & $C_{i s t}$ & $C_{i c u}$ \\
\hline Mean. & 8.2 & 8.3 & 9.9 & Min. & 6.5 & 5.2 & 8.7 \\
Max. & 10.7 & 12.2 & 11.1 & Number & 11 & 21 & 2 \\
\hline
\end{tabular}

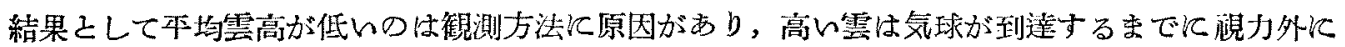

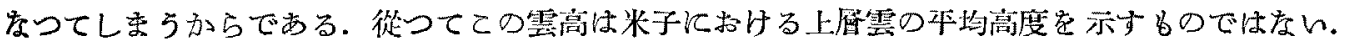

\section{§3. 上檿雲速}

雲高の場合之同じ意味で雲速（雲向を考慮しなん）の値を記しておく.(Table 2)

Table 2.

Mean velocity of high cloud at Yonago $(\mathrm{m} / \mathrm{s})$.

Mean velocity of high cloud at $\operatorname{Mera}(\mathrm{m} / \mathrm{s})$.

\begin{tabular}{l|c|c|c|c|c|c|c|c}
\hline & $C_{i}$ & $C_{i s t}$ & $C_{i c u}$ & & $C_{i}$ & $C_{i s t}$ & $C_{i c u}$ \\
\hline Mean. & 24 & 31 & 33 & Mean. & 30 & 27 & 23 \\
Number & 11 & 21 & 2 & Number & 66 & 26 & 33 \\
\hline
\end{tabular}

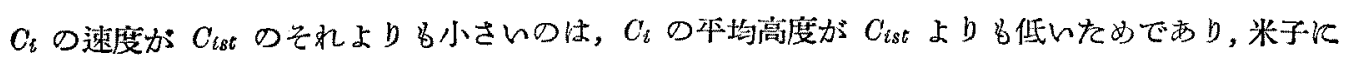

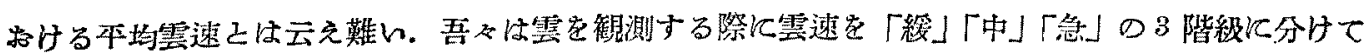


レるがこの目視観測の階䄲の区分が実際の雲速亡如何度る関係にあるかを知つておくこさは然意味

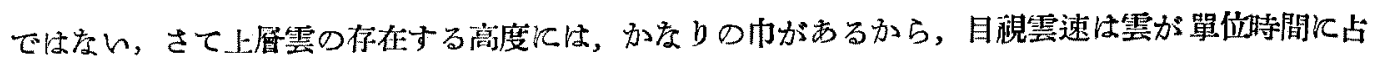
める視伤の大きさ之解さなければならない。

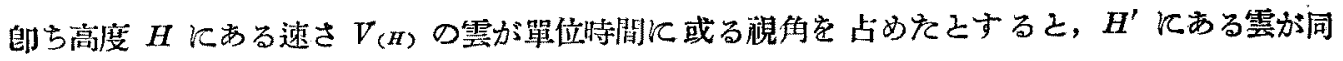
一の視角を占めるそめにはその雲速は

$$
V_{\left(H^{\prime}\right)}=V_{(H)} \times \frac{H^{\prime}}{H}
$$

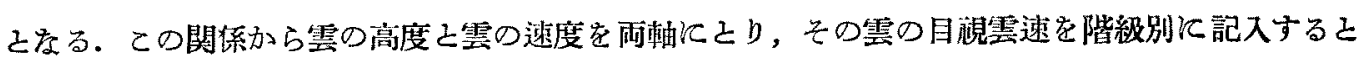

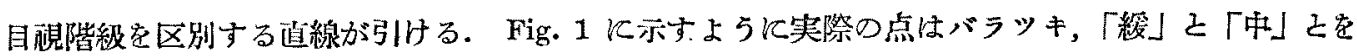
はつきり区別するととは難しいが，8 $\mathrm{km}$ で雲速 25 $\mathrm{m} / \mathrm{s}$ とする己図のよ5な近線が引け大体雨者安区別す ることが出来る.すなかち目視化よる上畨雲速の階級 区分は明猚之は云えないが「䜌」「中」を区別する管 速は雲高 $8 \mathrm{~km}$ で泟 $25 \mathrm{~m} / \mathrm{s}$ である。布良の報告(1) による之 $8 \mathrm{~km}$ の平均風速は $23 \mathrm{~m} / \mathrm{s}$ であるから, 平 均よりやや强いあたりから「中」之倠測されているよ うである.「急」之「中」之の区分は資料がをいので 触れるここは出来なん。図で点がバラックのは観測し

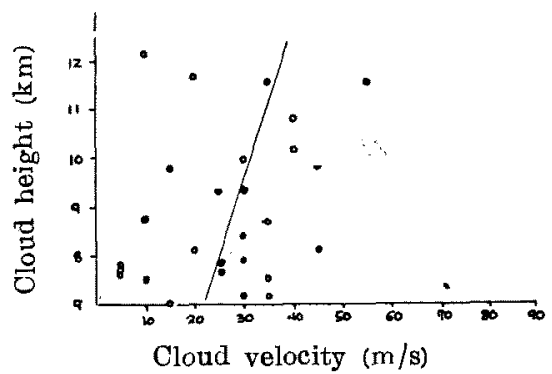

$\mathrm{O}$ : slow,

Fig. 1. Cloud velocity and its classification by sight.

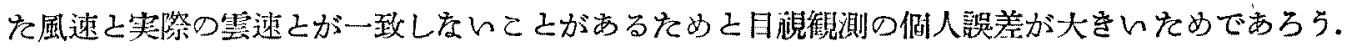

\section{§ 4. 上層雲層の気溫遞減率}

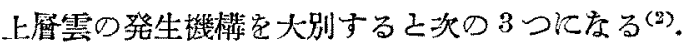

a) frontal surface Kよるもの,

b）部分的枯澚狣よるもの，

c）鿓通気流其他化子る8

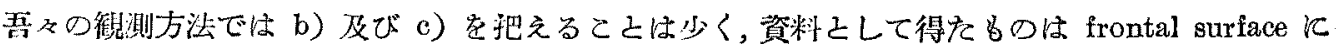

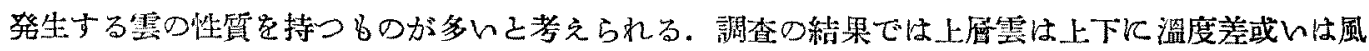

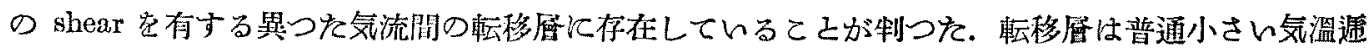

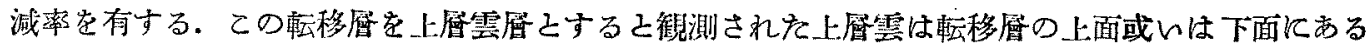

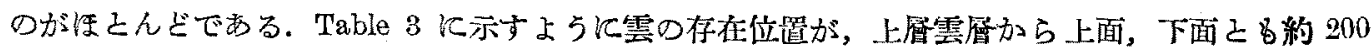
米の偏差があるが気球の上昇速度が約 $400 \mathrm{~m} /$ minute であるからこの偏差は分の端数で那捨てら

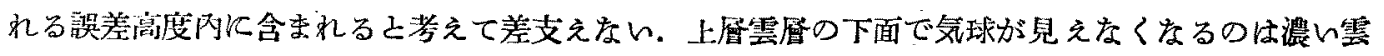
の場合であり，又上南で見えなくなるのは淡い堅の場合沉相当する. 以上のことから小さい気溫违 
Table 3. Height of high cloud and its deviation from the transitional layer.

\begin{tabular}{l|c|c|c|c|c}
\hline & $C_{b}$ & $C_{i s t}$ & $C_{i c u}$ & Mean of the deviation from the layer (m) \\
\hline Top of the layer & 3 & 9 & 1 & +240 \\
Inside of the layer & 1 & 5 & 0 & - \\
Base of the layer & 2 & 1 & 0 & -200 \\
\hline
\end{tabular}

Table 4. Temperature lapes rate of the high cloud layer.

\begin{tabular}{c|c|c|c|c|c}
\hline Lapse rate $\left({ }^{\circ} \mathrm{O} / 100 \mathrm{~m}\right)$ & $<0.02$ & $0.02 \sim 0.1$ & $0.1 \sim 0.2$ & $0.2 \sim 0.3$ & $0.3 \sim 0.4$ \\
\hline Number & 0 & 2 & 1 & 11 & 14 \\
\hline
\end{tabular}

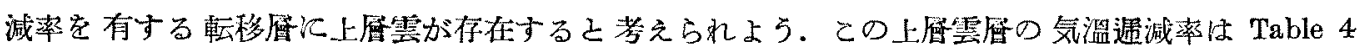

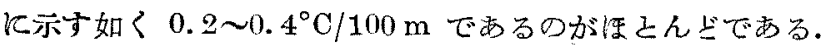

\section{§5. 上懕雲層の厚さ}

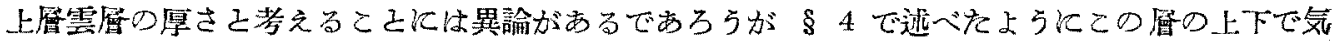

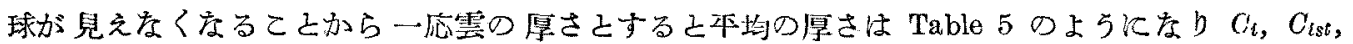

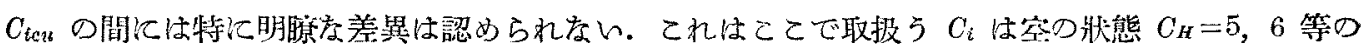
場合で $C_{i s t}$ 汇関聯しており厚い場命が多いためと考えられる。

Table 5.

Mean thickness of the high cloud layer.
Relation between thickness classification by sight and thickness of $C_{s}$-layer.

\begin{tabular}{l|r|r|r|r|r|r|r|r} 
& $C_{i}$ & $C_{i s t}$ & $C_{i \ell t}$ & & $C^{1}{ }_{i s t}$ & $C^{2}{ }_{i s t}$ & $C^{4}$ \\
\hline $\begin{array}{l}\text { Thist } \\
\text { Number }\end{array}$ & 510 & 520 & 400 & Thickness $(\mathrm{m})$ & 660 & 420 & 630 \\
\hline
\end{tabular}

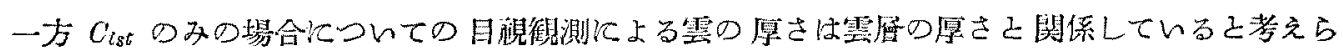

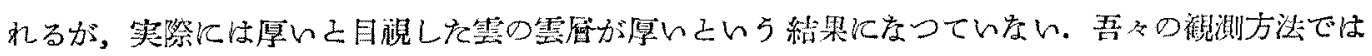

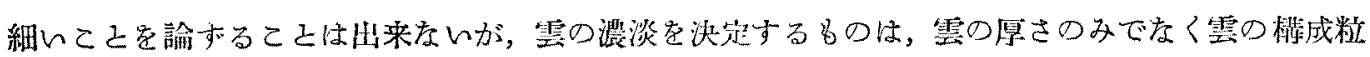
于 (水晶) の密度も考之る必要があるるいえよ5，下，中愿雲の場合には雲の厚さを制断する要素

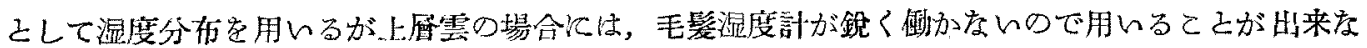
n.

\section{§ 6. 上層雲の湿度}

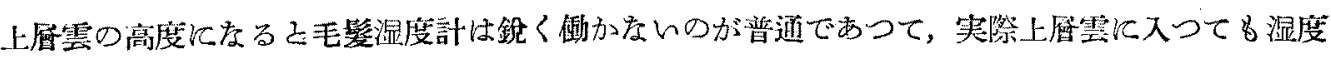

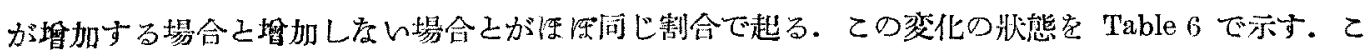

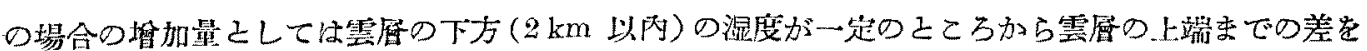

$$
-27=
$$


Table 6. Variation of hair-hygrometer in high cloud.

\begin{tabular}{l|c|c|c}
\hline Variation & increase & no change & decrease \\
\hline Number & 16 & 10 & 7 \\
Mean.: $\%)$ & 7.2 & & \\
\hline
\end{tabular}

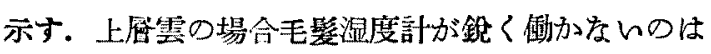

$$
F-f=\alpha \cdot \frac{d f}{d t}
$$

\section{$F$ : 実際の湿度, $f:$ 毛彭湿度計の示度, $\alpha$ : 遅差係数}

において溫度が低く湿度が小さいために $\alpha$ が大きくなるからである. 湿度が篔加しない場合が起

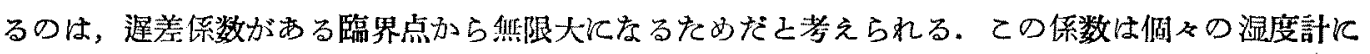

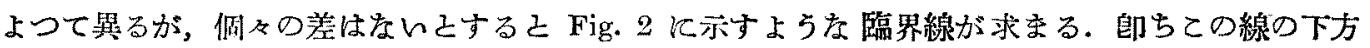
では湿度計は働かない，又上方でも真の湿度を示して

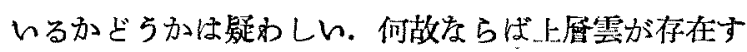
る以上少くとも水に対しては能和していると考えられ るが実際には遥か儿小さい湿度しか示さない，以上の

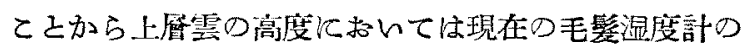
信賴度は低く，観測された湿度を種々の論䉝つために 使用するここは出来存ん。

\section{§ 7. 上層雲の溫庋}

上原雲の溫度としては純粹の水晶の雲が発生する溫 度之水晶の雲が存在する溫度之は别儿考えなければな らない. 即ち純粹の水晶が発生するのは実驗室內では $-41^{\circ} \mathrm{C}^{(3)}$ から生和るといわれているが，一方水晶の

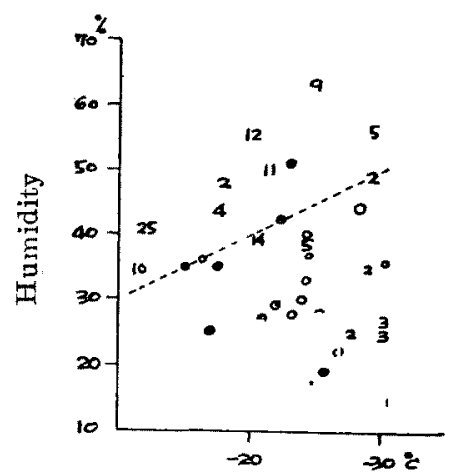

Temperature

$O$ : no change, $P$ : decrease numeral: increased humidity (\%)

Fig. 2. Relation between variation of hair-hygrometer in high cloud and its humidity and temperature.

存在する溫度こしては「等の結晶の研究」に上れば発生した氷晶は溫度及び過朎和度の変化によつ て㐫の形を变えて行くから，高度が变化する場合及 $C_{t} \rightarrow C_{t s t}$ の変化をする場合等には水蒸気の供

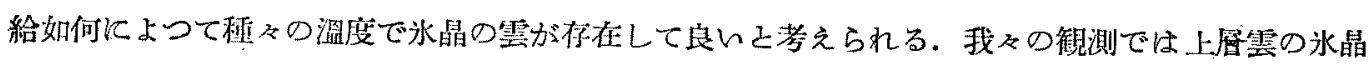

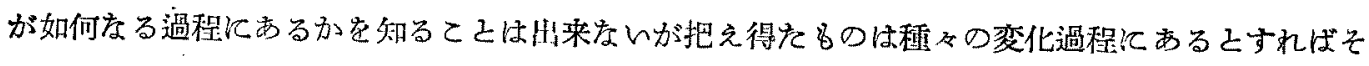

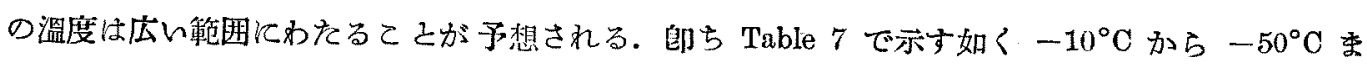

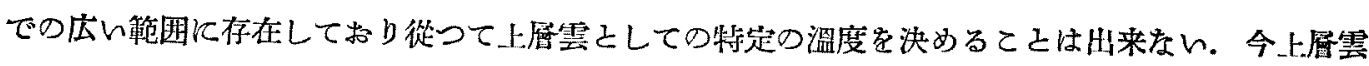
の位置をその溫度及び温度を座標として表わす之，Fig. 3 のょ5亿存在範围が規定され，その限界 線で㤬各々の溫度に対して湿度が異つており，低溫になるほど湿度が小さくても上居雲が存在して 
Table 7. Temperature of bigh cloud.

\begin{tabular}{c|c|c|c|c}
\hline Temperature range $\left({ }^{\circ} \mathrm{C}\right)$ & $-10 \sim-20$ & $-20 \sim-30$ & $-30 \sim-40$ & $-40 \sim-50$ \\
\hline Number & 5 & 8 & 6 & 3 \\
\hline
\end{tabular}

レる.て礼は「雪の結晶の研符」の結晶の分布図之同 じ偭向を持つており溫度，湿度につんての上原等の存 在条件を表わすもので放るがミ6で述へた如く湿度

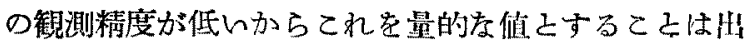
来存々。

\section{§ 8. 上層需層の解析}

今まで述へて来てのは上愿雲が存在するときの高原 気象要素己の関聯につんてであつた。，その結果上曆等

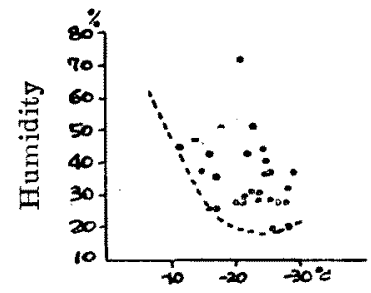

Temperature

Fig. 3. Existing limit of highes cloud by its bumiity and temperature.

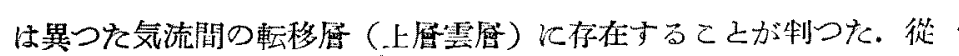

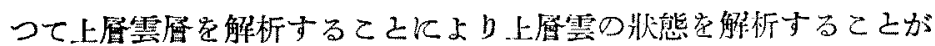

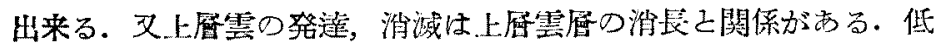
気压モデルでは良く知られているように笼気の移行上昇伅よつて転

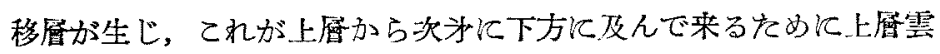

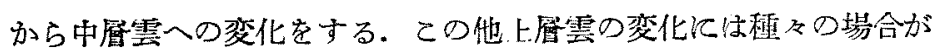
あるがこてで洁上愿雲が発達して行く場合上消娍する場合上の例を 示す.

1) 上曆雲発達の埸合

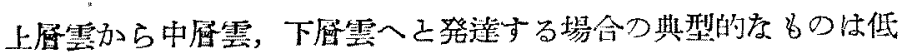
気王モデルに示されるよらな明膫索溫喛前線儿よる暖気の移行上昇 によつて起るが，乙の他に地上では明膫孝溫暖前線が現かれないる のにも赽つており，乙の場合はむしろ低気圧に上る暖気の侵入上解 倽すべをである.ての場合の1例を Fig. 4 亿示す.

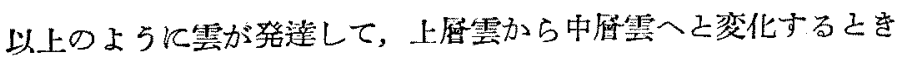
の解析の結果を綜合する之

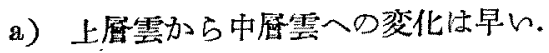

b) 上詹堅屡の気溫聥減率は小さく $0.2 \sim 0.3^{\circ} \mathrm{C} / 100 \mathrm{~m}$ の場合 が多く，上詹雲愿は地上に明膫を溫暖前線を体なわないときにも現 われる。
- lapse rate $0.2 \sim 0.3^{\circ} \mathrm{C} / 100 \mathrm{~m}$ .. lapse rate $0.3 \sim 0.4^{\circ} \mathrm{O} / 100 \mathrm{~m}$

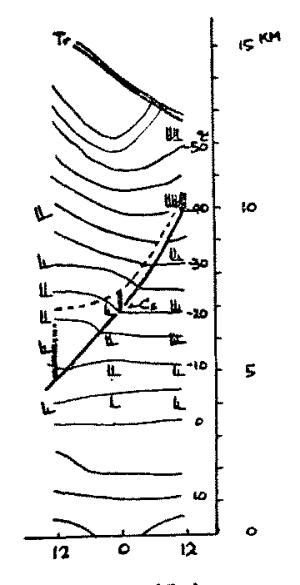

$$
12 \text { th } 11 \text { th }
$$

$10 A_{s}{ }^{2} \quad 10 C_{s}^{4} \quad 1 A_{c}$

$4 S_{c} \quad 2 S_{c} \quad 2 C_{a}$

Oct. 1949

Fig. 4 (1)

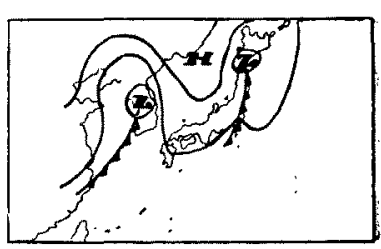

2Lh(I) 11. Oct. 1949

Fig. $4(2)$ 
c） $C_{t s t}$ は濃くて気球は上屏雲展の下面で消失する。

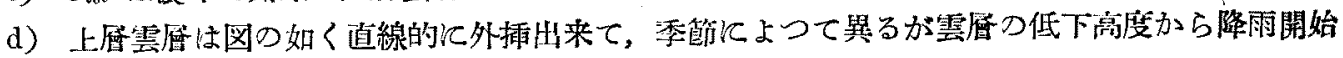
の予測が忧来る。

\section{2）上畨雲消滅の場合}

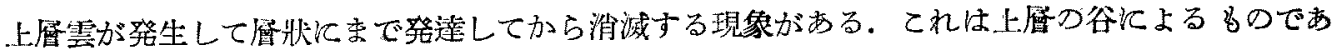

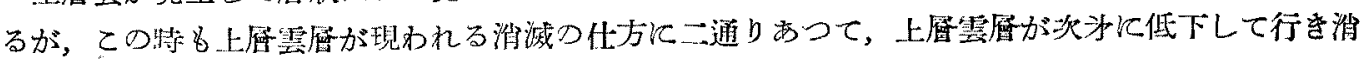

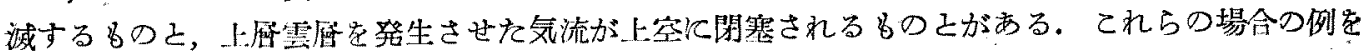
Fig. 5 及び Fig. 6 亿示す. これらの場合の解析の結果を綜合する之

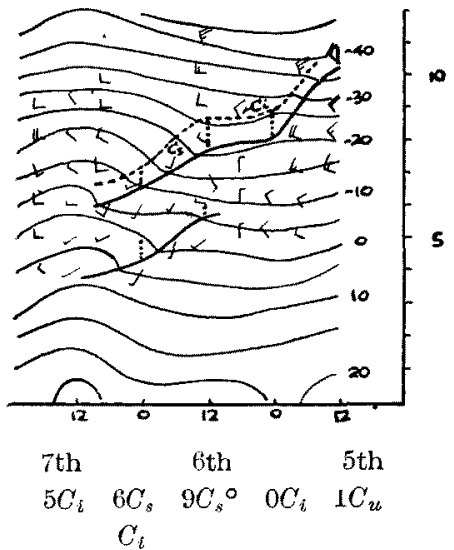

Sept. 1949

Fig. $5(1)$

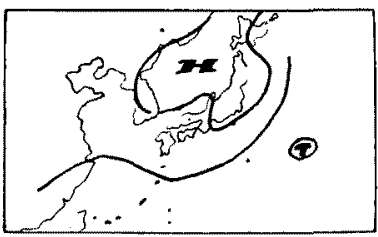

$09 \mathrm{~h}(\mathrm{I}) 6$ Sept. 1949

Fig. $5(2)$

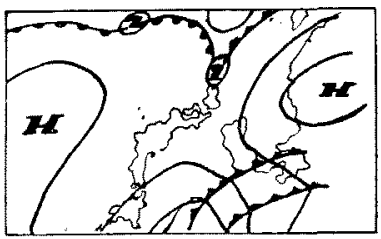

$21 \mathrm{~h}(\mathrm{I}) 14$ Mar. $195 \mathrm{l}$

Fig. $6(2)$

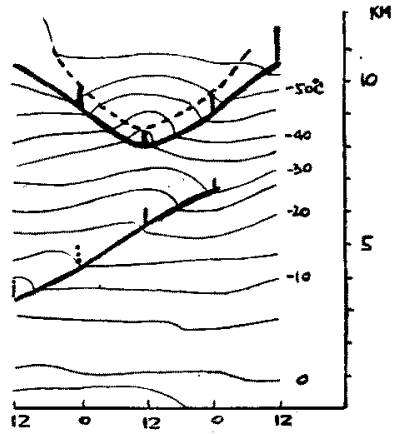

15 th 14 th 13 th

$0 \quad 10 C_{i} \quad 10 C_{i} \quad 5 C_{i} \quad 10 S_{c}$

$\begin{array}{ll}\boldsymbol{A}_{x}{ }^{\prime} & A_{c} \\ C_{u} & C_{u} \\ & C_{x}\end{array}$

Mar. 1951

Fig. $6(1)$

a)上詹雲愿つ気溫违減率は $0.3 \sim 0.4^{\circ} \mathrm{C} / 100 \mathrm{~m}$ のこが多く雲磨高度の時間的変化は小さい。

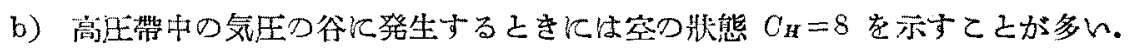

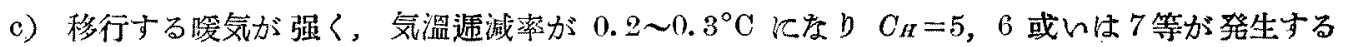
が，上空江閉塞してしま5ことがある。この場合 1）の発澾する場合との区別は難かしん，

\section{§ 9. 上層雲層の気温派減雍と空の狀態 $\left(C_{H}\right)$ との関俰}

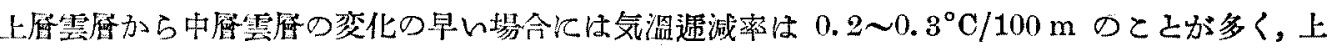

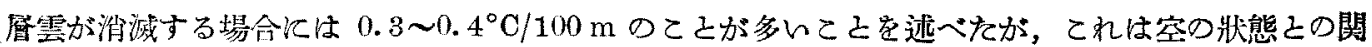

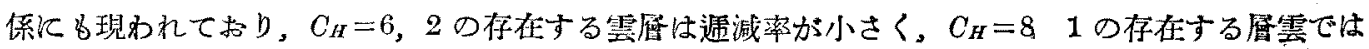
聥減率が大きい倾向がある. (Table 8)

Table 8. Relation between temperature lapse rate of high cloud layer and state of the sky $\left(C_{H}\right)$.

\begin{tabular}{c|c|c|c|c|c|c}
\hline \multirow{2}{*}{ Lapse rate $\left({ }^{\circ} \mathrm{C} / 100 \mathrm{~m}\right)$} & \multicolumn{7}{|c}{$C_{\boldsymbol{H}}$} \\
\cline { 2 - 7 } & 1 & 2 & 5 & 6 & 7 & 8 \\
\hline $0.02 \sim 0.1$ & 1 & - & - & - & - & 1 \\
$0.1 \sim 0.2$ & 1 & - & - & - & - & - \\
$0.2 \sim 0.3$ & - & 2 & - & 5 & 3 & 1 \\
$0.3 \sim 0.4$ & 3 & 1 & 1 & 2 & 3 & 4 \\
\hline
\end{tabular}


結

び

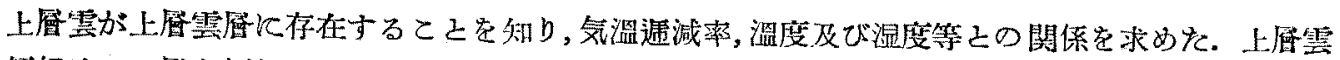
の解析はての屡を解析すれば良いて之を还べ,2,3の例を示した. 湿度及び测風の钼测精度が充分で ないために物足なさを感剠るこは否めない，風の shear に全然ふれていないのもこのためである。

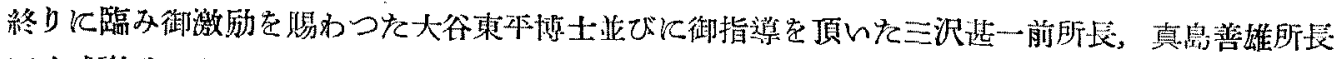
飞厚く感謝致します。

\section{文献}

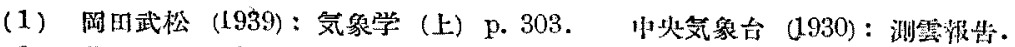

(2) 藤原唤平 (1939)：雲 p. 12.

(3) C. M. B. Dobson (1949) : Quart. Jour. Roy. Met. Soc., 75, 324, p. 126.

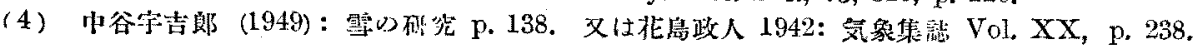

\section{要 報 Notes \\ 低気王內のポテンシャル・エネルギーの変化につレで}

榴 庭 信 -

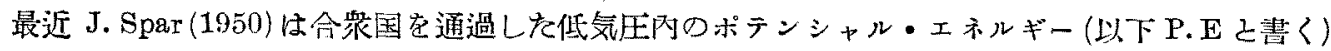

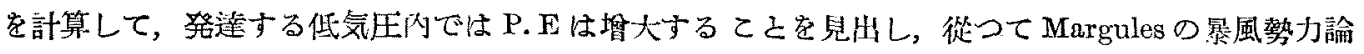

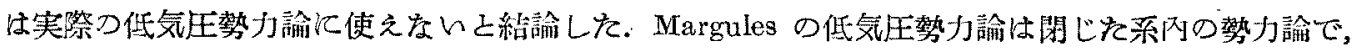
その基磷式は

$$
\Delta K=-\Delta(P+I)
$$

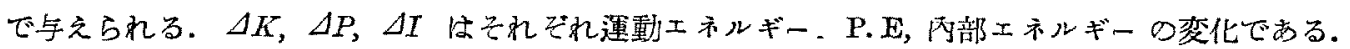

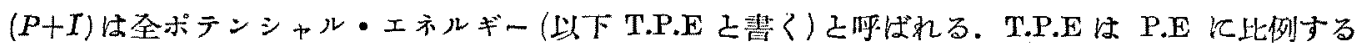
から，P.E の変化を見れば，T.P.E の变化が分る，從つて Spar の絬果は，発達する低気压內では

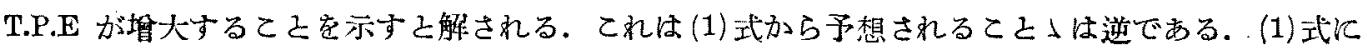
上れば $\Delta K \dot{K}>0$ こなるためには $-\Delta(P+I)>0$ ，つまり T.P.E は減少しなければならない. Spar

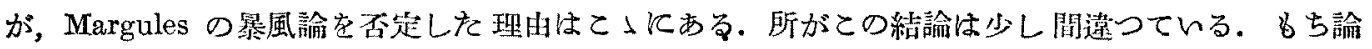
一般論としては，低気圧のエネルギー論と閉じを系のェネルギー理論をあてはめるのは正しくない

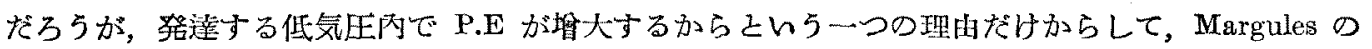

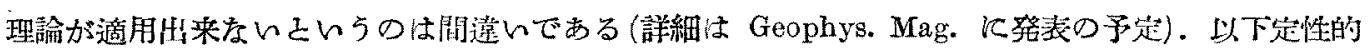
に方䛇りを指摘してみる。

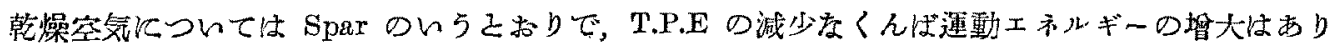

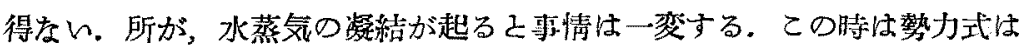

$$
\Delta K=-\Delta(P+I)+\Delta Q
$$

己なり， $\Delta Q$ は凝紹エネルギーの供給を示す. 閉じを系では， $-\Delta(P+I)$ は $\Delta Q$ の圂数で，一般に

$$
-\Delta(P+I)<0, \quad|\Delta(P+I)|<\Delta Q, \quad \Delta K>0
$$

亡なり，T.P.E は転危によつて增大するが，その際放仙される凝結エネルギーによつて相殺され， 結局運動エネルギーは增大する結果になる。乙れは低気圷內に水平温度倾度が存在するかどらかに

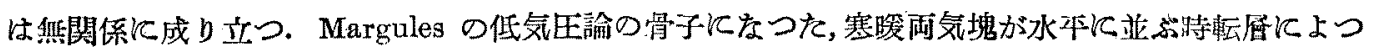
て放出されるエホルギーは，転詹が乾燥断熱的に起る時は，成程 T.P.E の減少に基づくが，転居

* S. Sakuraba: On the Change of Potential Energy in Cyclone.

$$
-31-
$$

